\title{
Development of Advanced-Laser Micro Dissection System for Protein Aggregation Diseases
}

\author{
Naomi Hachiya ${ }^{1 *}$ and Yoshimichi Kozuka ${ }^{2}$ \\ ${ }^{1}$ Research and Development Department, Biotechnology Group, Tokyo Metropolitan Industrial Technology Research Institute, Japan \\ ${ }^{2}$ Shinku-Device Instrument, Japan
}

Submission: February 11, 2018; Published: February 19, 2018

*Corresponding author: Naomi Hachiya, Research and Development Department, Biotechnology Group Tokyo Metropolitan Industrial Technology Research Institute, 2-4-10 Aomi, Koto-ku, Tokyo 135-0064 Japan, Tel: +81-3-5530-2111/+81-3-5530-2629; Email: hachiya.naomi@iri-tokyo.jp

\begin{abstract}
Results of the remarkable increase of life expectancy, the number of patients that have age-related diseases are increasing. Protein aggregation diseases are belonging to such diseases, and that submicron order of highly aggregated inclusions formed in tissues. Nowadays, effective therapeutic approaches are required, however, etiology of the diseases remain to be elucidated. One reason is that the size of inclusion is too small to purify without contamination especially in some disease cases thus we have difficulty in analyzing them biochemically. Therefore, it wouldn't be surprise that we hardly get reliable results even when we use a highly sensitive mass spectrometry in research. To solve this problem, we have developed an improved laser microdissection system; (Advanced-LMD) consisted of a deep ultraviolet laser with $266 \mathrm{~nm}$ of wavelength and fluorescent microscopy. Advanced-LMD can isolate minute size of inclusions derived from tissues.
\end{abstract}

Keywords: Laser micro dissection; Protein aggregation; Protein aggregation diseases; Aging; neurodegenerative diseases

\section{Introduction}

Conformational changes of proteins by aging evoke the protein aggregation diseases [1] such as cataract, as well as many neurodegerative diseases. In these diseases, various size of inclusions consisted of aggregated proteins are observed in the tissues and they are the important clue for knowing pathophysiological mechanisms of the diseases especially for sporadic/idiopathic cases. However, despite this importance, we realize that it is not easy to analyze of them because of the difficulty for isolation/purification and solubilization of them. In this mini review, we focus on the isolation/purification of protein aggregation disease-related inclusions, using laser micro dissection system (Hernandez and Lloreta 2006) which is the powerful tool for the protein analysis.

\section{Increase in protein aggregation diseases due to aging and its problems in analysis}

Many protein aggregation diseases are sporadic/idiopathic and age-related. For example, in an ocular diseases, many peoples are suffering from manage-related macular degeneration $[2,3]$ or cataract that aspartic acid of a-crystalline forms aggregation by converting from L-form to D-form $[3,4]$. In neurodegenerative diseases, Ab-peptide arising from a change in the physiological cleavage site of amyloid precursor protein causes abnormal aggregation and forms inclusion bodies extracellularly as senile plaques of Alzheimer's disease [5]. In sporadic/idiopathic case of Creutzfeldt-Jakob disease, which is a human prion disease, a normal prion protein predominantly in a-helix undergoes structural transformation to b-sheet and deposited as prion plaques [6].

The aging of a human body obviously come about aging of cells [7]. The morphology and functions of organelles are clearly different between young and aged cells; nuclei become enlarge [8], damage such as oxidative stress affects mitochondrial dynamics [9]. In addition, lipofuscin, peroxidized unsaturated fatty acid, accumulates in lysosomes due to the lysosomal dysfunction [10]. Proteasome deficiency impaired protein quality control systems and disabled cells to process proteins that have abnormal structure therefore, as a result, they are remained in the cytosol [11].

In the conventional biochemical protein analysis methods, firstly, tissue and cells are homogenized then centrifuged depending on the molecular size of contents. After that, 
various analytical methods are performed such as column chromatography, SDS-PAGE, CO-IP, Western bolting or mass spectrometry, etc. Of course, there is no objection that these methods are very effective in many cases, however, it should be remembered that these techniques have been optimized for "young normal cells". When we use "aged cells" as materials, homogenization does not work well as same as young cells, therefore, in the subsequent steps such as centrifugation, accurate separation becomes to be difficult, so contamination is unavoidable. If solubilization does not go well because of the protein aggregation, the subsequent analysis also more and more difficult, thus the acquired results will not be reliable. Of course, the fact is, if homogenization and centrifugation are carried out, it is impossible to avoid contamination even with young cells, so this method is basically not optimal way especially when we use a highly sensitive mass spectrometer. Hence, this is one of the reason why the true constituent of the disease-related deposits is hardly determined by using mass spectrometry. To compensate for this shortcoming, there is an ideal method; laser micro dissection (LMD) system. This is made from laser and microscopy regions and objective targets are cut out from the surroundings by irradiation of laser pulse.

\section{History of LMD method}

LMD is now available as a method for isolating a target in place of homogenization and centrifugation. In the LMD method, target material is obtained under a microscope observation, thus it enables us to isolate target only as possible. Therefore, this method is an extremely excellent technique that can suppress contaminations.

LMD was firstly invented by Sergej Stepanovich Tscashotin [12]. It is believed that Sergej is supposed to have come up with the idea of LMD based on the story of "Archimedes thermal light"; Anecdote that Archimedes gathers sunlight with a mirror and blows enemy ships at the battle of Syracuse in the second Poeni war. Incidentally, his life was eventful, and he has been also known as a political activist. Sergej was born in 1883 at Constantinople between Russian father and Greek mother at Constantinople in Turkey. In 1901, he entered the Moscow University Medical School (now Lomonosov Moscow State University) in Russia as a medical student, but he was deported to Constantinople by participating in the political student movement. After that he went to Germany and got a degree in biophysics and zoology from the university Heidelberg, then returned to Russia again in 1912 and was present at the laboratory of professor Ivan Pavlov that has been famous for "conditioned reflex" study. However, once again Sergej was passionate about the extreme political activities of the Russian revolution. For example, he used a printer of Pavlov's lab to print propaganda of revolution and took out nitroglycerin from the laboratory and gave it to the revolutionary. With these various events, Pavlov's patience was worn out and he was approached Sergej to choose between "Science or Politics". For this reason, in 1917, Sergej left Pavlov's lab. Later he appointed as a professor to Zagreb University in Russia (now Croatia) in 1920, but in the following year he was unemployed due to labor dispute. In 1927, he worked at the Russian Embassy in Berlin, and he had friendship with Albert Einstein, this event led him to back to be a scientist [13].

The LMD method developed Sergej Tscashotin has been improved continuously with the advancement of applied laser to date. Currently, LMD system is commercially available from several manufactures as a laser capture microdissection system [14]. In this method, target region is irradiated by laser then dropping on or flipping up to a heat absorbing film for recovery. Commercially available laser capture microdissection equipment uses the $350 \mathrm{~nm}$ of wavelength for cutting in generally, this is because the wavelength has a high thermal energy. This method is widely used for isolation of tumor cell masses such as cancer cells, and after the cutting of specimens, nucleic acid is taken out from them for genome analysis. In recent years, LMD also can isolates a single cell which has the $20 \sim$ or $30 \sim \mathrm{mm}$ in diameter.

However, even with this evolutionary system, sometimes we have faced difficulty to isolate protein inclusions, especially aggregated form of them because they are too small to pick out from tissues even using the LMD system. The sizes of diameter are few micron meters, for example, Pick bodies of Pick's disease has 4 mm [16-18], Bunina bodies of amyotrophic lateral sclerosis has only 1 mm [19]. Therefore, the application of laser capture microdissection system is mostly limited to large size targets, such as amyloid of senile plaques exceeding $\sim 10 \mathrm{~mm}$ in diameter, which deposit outside of cells [20-22]. For this reason, to solve this problem we have developed an improved and advanced type of LMD system that can cut very small regions with an efficient recovery method.

\section{Development of improved LMD (Advanced-LMD) method}

To cut the small region of disease derived inclusions, we used the laser which has a wavelength of $266 \mathrm{~nm}$ corresponding to deep ultraviolet, it is used for processing of semiconductor or liquid crystal at the industrial level. The laser was connected to a fluorescence microscopy (Figure 1a) and cut inclusions observing through an objective lens that can pass through 266 $\mathrm{nm}$. According to the changing of laser wavelength from 350 $\mathrm{nm}$ to $266 \mathrm{~nm}$, we changed cutting strategy. In the general LMD system, around of the target was traced by laser and irradiate to cut them, on the contrary, in our method, we leave the target on the field of view and burn up the target surroundings by $266 \mathrm{~nm}$ of laser system. This method can avoid mixing of unnecessary contaminations to the utmost. We also have changed recovery system. In laser capture system, the target is dropped or bounced up from the slide glass and stuck to adsorbent film for the recovery. However, since there is a plurality of deposits found in tissue specimens of protein aggregation diseases on a slide, it is impossible to catch up them "one by one" using heat 
absorbing film system for collection. Therefore, we developed new way using capillarity as below; firstly, we remain targets only on a slide glass for burning out the surroundings, then one drop of distilled water was added to cover the targets. When a glass tube is brought close to a dropped water on slide glass, targets are sucked into the tube due to capillarity between the water and the glass tube (Figure 1b). Using this system, we can recover 100 s of targets at once and easily.

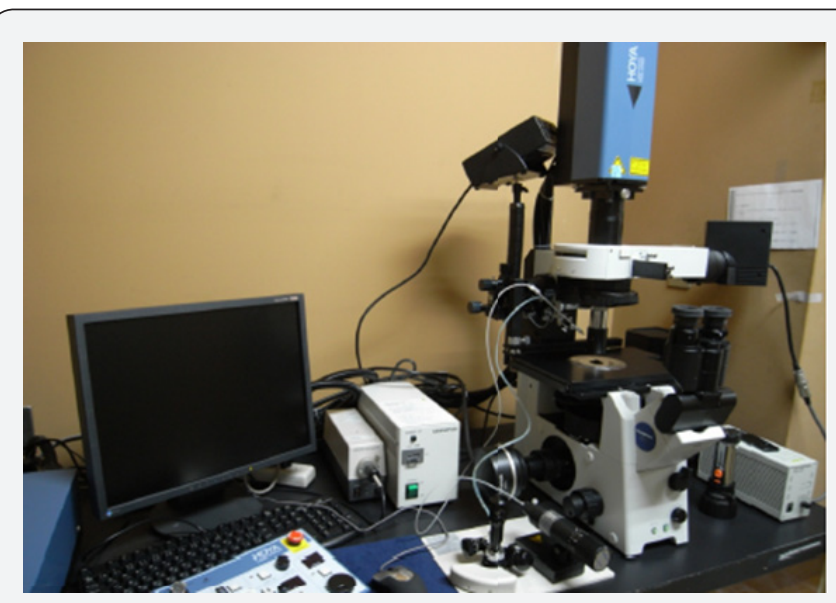

Figure 1a: (a) Advanced-LMD we have developed. $266 \mathrm{~nm}$ of the laser device is combined to the fluorescent microscopy.

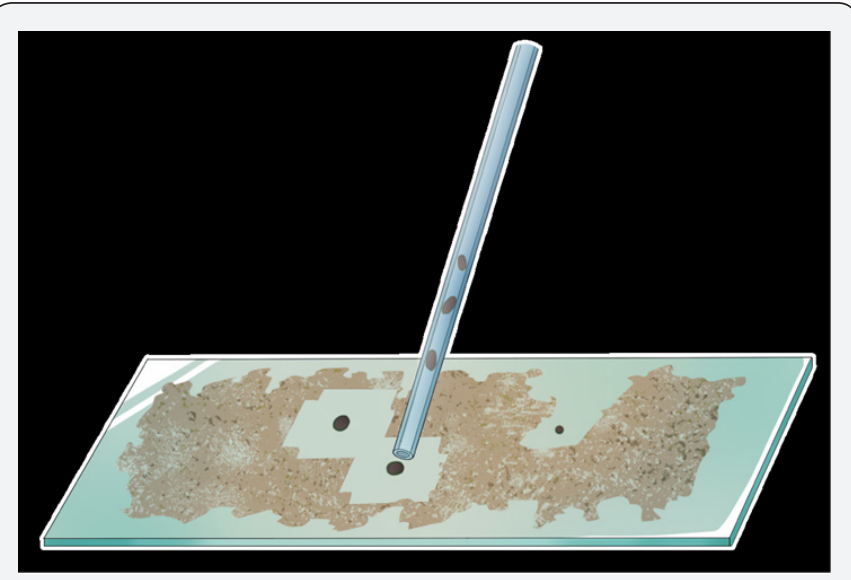

Figure 1b: (b) Sample recovery system of Advanced-LMD. Glass tube was used for capillarity.

Figure 1: Advanced-laser micro dissection (LMD) system.

\section{Conclusion}

Protein aggregation diseases such as Alzheimer's disease, Pick's disease or amyotrophic lateral sclerosis are mostly caused by aging, and it is thought that the prevalence rate has been continuing to increase with the prolongation of average life expectancy. However, mechanisms of these protein aggregated and age-related diseases are remained to be elucidated, thus unfortunately we don't have exact way of prophylactic or therapeutic methods to date. One reason for this problem is that inclusions made from abnormally aggregated proteins are difficult to analyze because of the difficulty of isolation/ purification of them. To solve this problem, recently we developed an improved LMD (Advanced-LMD) system. With this, disease-derived inclusions were isolate easily without contamination and they would be suitable for the very sensitive method such as high spec mass spectrometry. These analytical methods will disclose the etiology of age-related and protein aggregated diseases and break a path for a new therapeutic method in future.

\section{Acknowledgement}

I would like to express my gratitude to Grants- in-Aid for Scientific Research and grand for the fundamental research of TIRI.

\section{Conflict of Interest}

The authors declare no competing financial interest.

\section{References}

1. Avila CL, Chaves S, Socias SB, Vera-Pingitore E, González-Lizárraga F, et al. (2017) Lessons learned from protein aggregation: toward technological and biomedical applications. Biophys Rev 9(5): 501-515.

2. Baker DJ, Peleg S (2017) Biphasic Modeling of Mitochondrial Metabolism Dysregulation during Aging. Trends Biochem Sci 42(9): 702-711.

3. Bigio EH (2013) Making the diagnosis of frontotemporal lobar degeneration. Arch Pathol Lab Med 137(3): 314-325.

4. Blasiak J, Piechota M, Pawlowska E, Szatkowska M, Sikora E, et al. (2017) Cellular Senescence in Age-Related Macular Degeneration: Can Autophagy and DNA Damage Response Play a Role? Oxid Med Cell Longev 2017: 5293258.

5. Datta S, Malhotra L, Dickerson R, Chaffee S, Sen CK, et al. (2015) Laser capture microdissection: Big data from small samples. Histol Histopathol 30(11): 1255-1269.

6. Fujii NT, Takata N, Fujii K (2016) Isomerization of aspartyl residues in crystallins and its influence upon cataract." Biochim Biophys Acta 1860(1 Pt B): 183-191.

7. Godsave SF, Peters PJ, Wille H (2015) Subcellular distribution of the prion protein in sickness and in health. Virus Res 207: 136-145.

8. Greulich OK (2007) Chapter 27: Sergej Stepanovich Tschachotin: Experimental Cytologist and Political Critic (1883-1973). Method in Cell Biology, pp.725-734.

9. Guha S, Liu J, Baltazar G, Laties AM, Mitchell CH (2014) Rescue of compromised lysosomes enhances degradation of photoreceptor outer segments and reduces lipofuscin-like autofluorescence in retinal pigmented epithelial cells. Adv Exp Med Biol 801: 105-111.

10. Hachiya NS, Ohkubo T, Kozuka Y, Yamazaki M, Mori O, et al. (2005) More than a 100 -fold increase in immunoblot signals of laser-microdissected inclusion bodies with an excessive aggregation property by oligomeric actin interacting protein 2/D-lactate dehydrogenase protein 2 . Anal. Biochem 347(1): 106-111.

11. Hernández S, Lloreta J (2006) Manual versus laser micro-dissection in molecular biology. Ultrastruct Pathol 30(3): 221-228.

12. Higuchi-Sanabria R, Frankino PA, Paul JW, Tronnes SU, Dillin A (2018) A Futile Battle? Protein Quality Control and the Stress of Aging. Dev Cell 44(2): 139-163.

13. Hodne KWF (2015) Single-Cell Isolation an Gene Analysis: Pitfalls and Possibilities. Int J Mol Sci 16: 26832-26149. 
14. Hohn AD, Weber T, Jung C, Ott M, Hugo B, et al. (2017) Happily (n)ever after: Aging in the context of oxidative stress, proteostasis loss and cellular senescence. Redox Biol 11: 482-501.

15. Jeong S (2017) Molecular and Cellular Basis of Neurodegeneration in Alzheimer's Disease. Mol Cells 40(9): 613-620.

16. Klaips CL, Jayaraj GG,. Hartl FU (2018) Pathways of cellular proteostasis in aging and disease.J Cell Biol 217(1): 51-63.

17. Korovila I, Hugo M, Castro JP, Weber D, Höhn A, et al. (2017) Proteostasis, oxidative stress and aging. Redox Biol 13: 550-567.

18. Mori F, Kakita A, Takahashi H, Wakabayashi K (2014) Co-localization of Bunina bodies and TDP-43 inclusions in lower motor neurons in amyotrophic lateral sclerosis. Neuropathology 34(1): 71-76.
19. Ohkubo T (2006) Three-repeat Tau 69 is a major tau isoform in lasermicrodissected Pick bodies. Amyloid 13(1): 1-5.

20. Tshachotin S (1912) Die mikroskopishe Strahlenstichmethode, eine Zelloperationsmethode. Biol Zentralbl 32: 623-630.

21. Stewart KL, SE Radford (2017) Amyloid plaques beyond Abeta: a survey of the diverse modulators of amyloid aggregation. Biophys Rev 9(4): 405-419.

22. Yazaki M, Yoshinaga T, Sekijima Y, Nishio S, Kanizawa Y, et al. (2015) The first pure form of Ostertag-type amyloidosis in Japan: a sporadic case of hereditary fibrinogen Aalpha-chain amyloidosis associated with a novel frameshift variant. Amyloid 22(2): 142-144.

\begin{tabular}{|l|}
\hline \multicolumn{1}{|c|}{ Your next submission with Juniper Publishers } \\
will reach you the below assets \\
- Quality Editorial service \\
- Swift Peer Review \\
- Reprints availability \\
- E-prints Service \\
- Manuscript Podcast for convenient understanding \\
- Global attainment for your research \\
- Manuscript accessibility in different formats \\
( Pdf, E-pub, Full Text, Audio) \\
- Unceasing customer service \\
Track the below URL for one-step submission \\
https://juniperpublishers.com/online-submission.php \\
\hline
\end{tabular}

